\title{
Combined deletion of Xrcc4 and Trp53 in mouse germinal center $B$ cells leads to novel B cell lymphomas with clonal heterogeneity
}

Zhangguo Chen ${ }^{1,2}$, Mihret T. Elos ${ }^{1}$, Sawanee S. Viboolsittiseri ${ }^{1}$, Katherine Gowan ${ }^{4}$, Sonia M. Leach ${ }^{2,3}$, Michael Rice ${ }^{1}$, Maxwell D. Eder ${ }^{1}$, Kenneth Jones ${ }^{4}$ and Jing H. Wang ${ }^{1,2^{*}}$

\begin{abstract}
Background: Activated B lymphocytes harbor programmed DNA double-strand breaks (DSBs) initiated by activationinduced deaminase (AID) and repaired by non-homologous end-joining (NHEJ). While it has been proposed that these DSBs during secondary antibody gene diversification are the primary source of chromosomal translocations in germinal center (GC)-derived B cell lymphomas, this point has not been directly addressed due to the lack of proper mouse models.

Methods: In the current study, we establish a unique mouse model by specifically deleting a NHEJ gene, Xrcc4, and a cell cycle checkpoint gene, Trp53, in GC B cells, which results in the spontaneous development of $B$ cell lymphomas that possess features of GC B cells.

Results: We show that these NHEJ deficient lymphomas harbor translocations frequently targeting immunoglobulin (Ig) loci. Furthermore, we found that $\mathrm{g}$ translocations were associated with distinct mechanisms, probably caused by AID- or RAG-induced DSBs. Intriguingly, the AID-associated Ig loci translocations target either c-myc or Pvt-1 locus whereas the partners of RAG-associated I $g$ translocations scattered randomly in the genome. Lastly, these NHEJ deficient lymphomas harbor complicated genomes including segmental translocations and exhibit a high level of ongoing DNA damage and clonal heterogeneity.
\end{abstract}

Conclusions: We propose that combined NHEJ and p53 defects may serve as an underlying mechanism for a high level of genomic complexity and clonal heterogeneity in cancers.

Keywords: Non-homologous end-joining, Genomic instability, Chromosomal translocations, B cell lymphoma, Clonal heterogeneity

\section{Background}

The occurrence of human B cell lymphomas is much more frequent than that of $\mathrm{T}$ cell lymphomas [1]. This phenomenon might be attributed to the multiple mechanisms functioning in B lymphocytes that intrinsically generate DNA double-stranded breaks (DSBs) or mutations $[2,3]$. Developing B cells in the bone marrow (BM)

\footnotetext{
* Correspondence: jing.wang@ucdenver.edu

${ }^{1}$ Department of Immunology and Microbiology, University of Colorado, Anschutz Medical Campus, 12800 E. 19th Ave, Mail Stop 8333, Aurora, CO 80045, USA

${ }^{2}$ Department of Biomedical Research, National Jewish Health, Denver, CO 80206, USA

Full list of author information is available at the end of the article
}

undergo $\mathrm{V}(\mathrm{D}) \mathrm{J}$ recombination to assemble the variable $(\mathrm{V})$ region exons of $I g$ genes $[4,5] . V(D) J$ recombination involves a cut-and-join mechanism initiated by the lymphocyte-specific RAG1/2 endonucleases that recognize and introduce DSBs at recombination signal sequences (RSS) flanking germline V, D, and J segments [6]. Subsequently, broken $\mathrm{V}, \mathrm{D}$, and J segments are joined by ubiquitous non-homologous end-joining (NHEJ) [7]. Ongoing RAG-expression in newly generated B cells allows secondary $\mathrm{V}(\mathrm{D}) \mathrm{J}$ recombination, termed "receptor editing", a process in which additional $I g$ gene rearrangements may occur in BM immature B cells [8-12]. Ultimately, RAG 
down-regulation in mature B cells prohibits further $\mathrm{V}(\mathrm{D}) \mathrm{J}$ rearrangement [13, 14]. However, our previous studies suggest that mature B cells may also undergo secondary $\mathrm{V}(\mathrm{D}) \mathrm{J}$ recombination at low frequency in an in vitro culture system [15]. While RAG contributes to the genomic instability of developing B cells [16-18], its role in mature $B$ cell lymphomagenesis is still under debate.

Upon antigen activation, mature B cells undergo further genetic diversification processes, namely, class switch recombination (CSR) and somatic hypermutation (SHM), in specialized secondary lymphoid structures termed germinal centers (GCs) [19-22]. Activation-induced deaminase (AID) initiates CSR and SHM [23, 24], which deaminates cytosines in transcribed DNA and ultimately causes DSBs or point mutations [25-28]. CSR is a regionspecific deletional recombination process required for producing isotype-switched antibody such as IgG [29]. AID-initiated DSBs occur at the switch (S) regions within the Igh locus, which are eventually resolved as deletions in cis on the same chromosomes, thereby causing the switch of constant regions of Igh [29]. SHM introduces predominantly point mutations into IgH and IgL $\mathrm{V}$ region exons, allowing the selection of B cell clones with increased affinity for antigen [27]. Besides Ig loci, AID can target non-Ig loci to induce genetic lesions, thereby posing a threat to genome stability [30]. Consistently, the dysregulated AID activity contributes to tumorigenesis [31, 32]. We and others have shown that AID is required for generating chromosomal breaks at the Igh locus [15] and the Igh-c-myc translocations [33].

Apart from programmed DSBs, B lymphocytes harbor general DSBs arising from genotoxic agents such as oxidative damage or DNA replication errors. To preserve genome integrity, two major DSB repair pathways operate in mammalian cells: homologous recombination (HR) and NHEJ. While HR-directed repair requires homologous templates, NHEJ can repair DSBs with little or no sequence homology [34]. The NHEJ pathway joins programmed DSBs in lymphocytes including RAG- or AID-initiated DSBs [35] and repairs general DSBs in all types of cells [34]. The NHEJ pathway includes Ku70, Ku80, DNA-PKcs, XLF, Artemis, XRCC4, and DNA Ligase 4 (Lig4) [34]. XRCC4, Lig4, and possibly XLF form a complex to catalyze the end-ligation step of NHEJ [34, 36]. Germline deletion of NHEJ results in severe combined immune deficiency due to inability to complete V(D)J recombination [4, 7]. Conditional deletion of Xrcc4 or Lig4 in peripheral B cells reduces the CSR level and causes a high level of chromosomal breaks and translocations at the Igh locus due to inability to repair AIDinitiated DSBs [15, 37]. While defective DSB repair leads to genomic instability, cell cycle checkpoints can protect organisms from adverse downstream effects, such as transformation, by eliminating damaged cells.
As DSB repair and checkpoint mechanisms complement each other, loss of both can cause dramatic predisposition to transformation in mouse lymphocytes, often leading to lymphomas due to the inappropriate repair of programmed or general DSBs [38]. For instance, deficiency of Xrcc4, Lig4, and Xrcc6 (Ku70) in conjunction with $\operatorname{Trp} 53$ deficiency causes pro-B cell lymphomas carrying co-amplified Igh-c-myc loci [39-43]. TP53 is a well-known tumor suppressor gene, which encodes p53 protein capable of responding to diverse cellular stresses by regulating the expression of its target genes, thereby inducing cell cycle arrest, apoptosis, or senescence, modulating DNA repair or metabolism and serving as the guardian of the genome [44-46].

We previously showed that conditionally deleting $\mathrm{Xrcc} 4$ in Trp53-deficient peripheral B cells resulted in the development of surface Ig negative lymphomas from editing and switching B cells (termed CXP lymphomas) [47]. Although CXP tumors have mature B cell characteristics, they appear to be very different from human mature B cell lymphomas. For instance, CXP lymphomas do not express IgH or IgL chain protein on the surface or intracellularly and show no SHM in the rearranged VDJ exon [47]. In contrast, most of human mature B cell lymphomas are surface Ig positive except classical Hodgkin's lymphoma and a few others [1]. These differences suggest that the mechanism of lymphomagenesis and the developmental stage of tumor progenitors are very different between CXP and human mature B cell lymphomas. Such difference may be due to the relatively early deletion of $X r c c 4$ via $\mathrm{CD} 21 \mathrm{cre}$. $\mathrm{CD} 21$ begins to be expressed between the immature and the mature $B$ cell stages, specifically in transitional B cells [48]. Thus, in mice performing CD21cre-mediated Xrcc4 deletion, it is likely that some DSBs are generated before the cells are recruited into the GC reaction. In the current study, we delete $X r c c 4$ and Trp53 at a later stage of mature B cell development during the $\mathrm{GC}$ reaction, which leads to $\mathrm{B}$ cell lymphomas that possess GC B cell features and harbor frequent $I g$ loci translocations, ongoing DNA damage and a high level of clonal heterogeneity.

\section{Results}

Deletion of Xrcc4 but not Trp53 via C 1 1cre leads to a high level of genomic instability at the Igh locus

We established a new mouse model in which $\operatorname{Xrcc} 4(X)$ and $\operatorname{Trp53}(P)$ genes were deleted at a later stage of mature B cell development using $\mathrm{C} \gamma 1 \mathrm{Cre}$ [49]. In Cy1Cre knock-in mice, Cre expression is driven by the endogenous $\mathrm{I} \gamma 1$ promoter and occurs in the majority of GC B cells [49]. Consistently, we found that GC B cells have the complete deletion of $X r c c 4(X)$ floxed allele in $C \gamma 1 C r e / X^{c /+}$ mice (c: floxed allele; +: wt allele) (Additional file 1: Figure S1A). Then, we examined 
whether deletion of $X r c c 4$ or $\operatorname{Trp53}$ via Cy1cre led to a high level of genomic instability in primary B cells. To do so, we assayed for Igh locus-specific genomic instability in $\mathrm{B}$ cells that can be induced via anti-CD40/IL4 activation in the in vitro culture of primary B cells $[15,37]$. Using metaphase fluorescence in situ hybridization (FISH), we found that anti-CD40/IL4-stimulated Xrcc4/Trp53double deficient (DKO) B cells harbored a high level of
Igh locus instabilities, including breaks and translocations (Fig. 1a, b). Furthermore, our data showed that Xrcc4 deficiency alone resulted in a high level of $I g h$ locus genomic instability; in contrast, $\operatorname{Trp} 53$ deficiency did not enhance the level of genomic instability in activated B cells compared to wt controls (Fig. 1a). Thus, the Igh locus genomic instability in the DKO B cells is largely attributable to $X r c c 4$ deficiency.

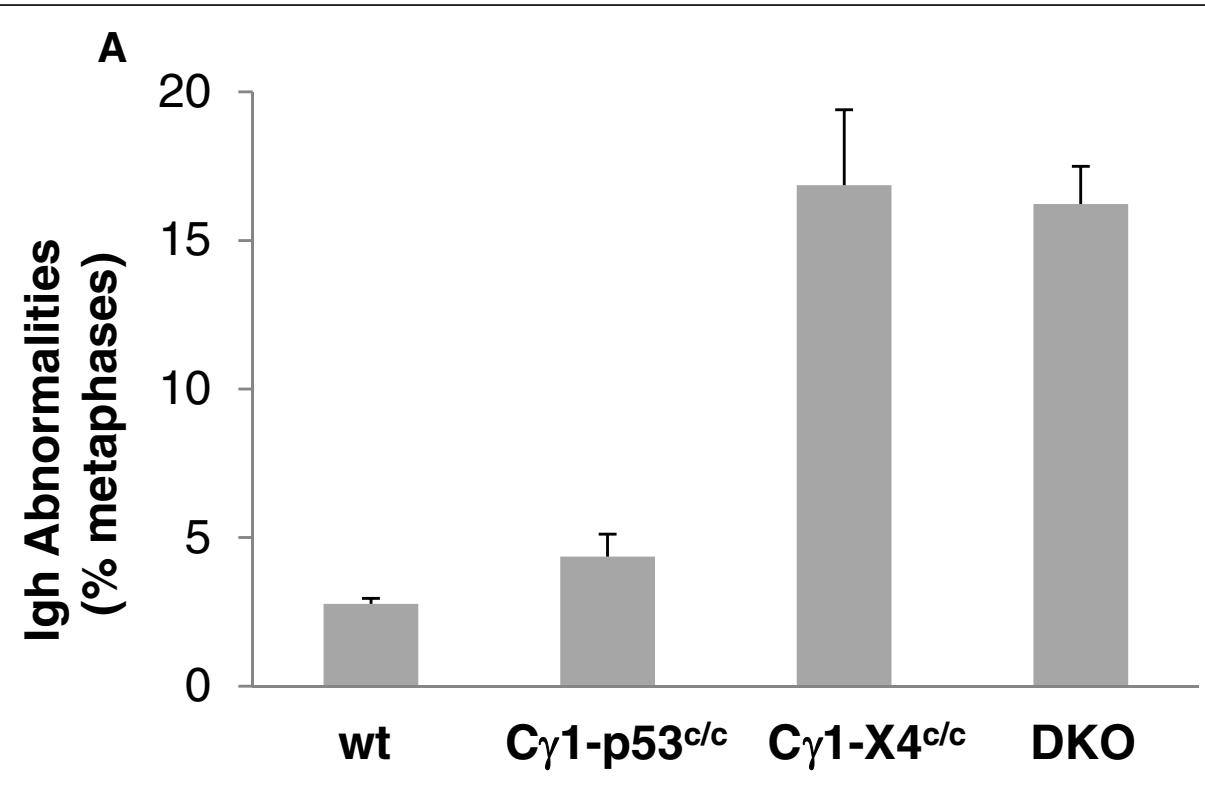

B

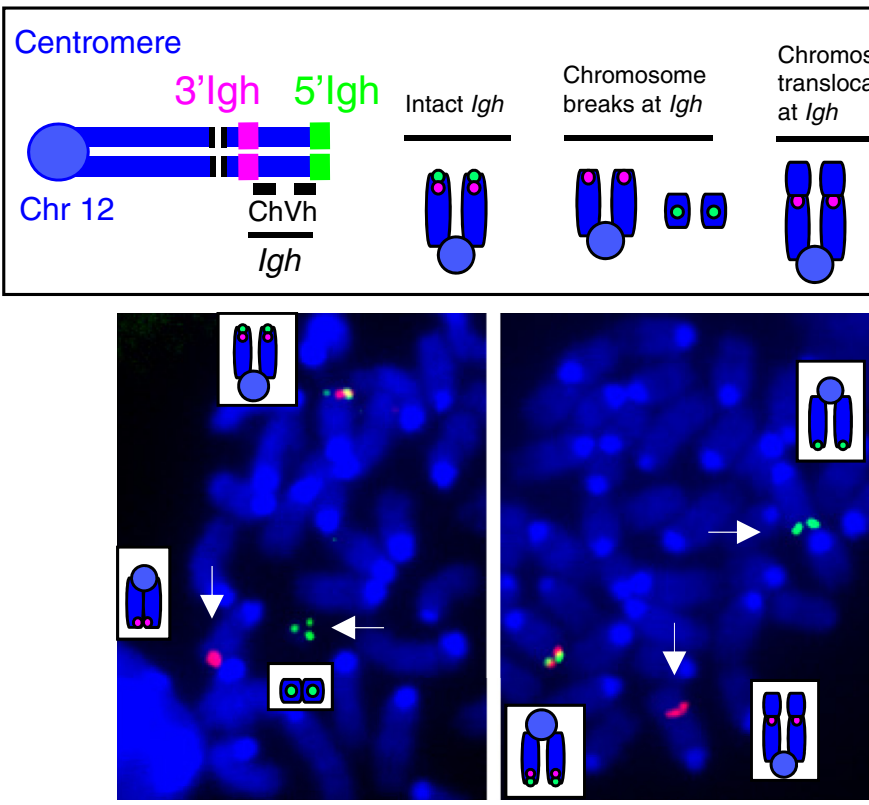

Fig. 1 Deletion of Xrcc4 but not Trp53 via C 1 cre leads to a high level of genomic instability at the Igh locus. a Quantification of Igh abnormalities in day 4 anti-CD40/IL4-activated wt $(n=6), C \gamma 1-p 53^{c / c}(n=4), C \gamma 1-X 4^{c / c}(n=3)$, and DKO $(n=6)$ splenic B cells. Data are presented as mean \pm s.e.m. Statistical analyses were calculated by a Student's $t$ test with two-tailed distribution and equal variance. $p=0.024$ (control vs C 1 1-p53/c), $p=6.78 \mathrm{E}-05$ (control vs $C Y 1-X 4^{c / c}$ ), $p=1.03 \mathrm{E}-06$ (control vs DKO), $p=0.805$ (CY1-X4 ${ }^{c / c}$ vs DKO). b Top: Diagram of lgh metaphase FISH probes and abnormalities. An intact Igh shows co-localized red and green signals while a broken locus appears as split red and green signals. Bottom: Example of metaphase FISH showing lgh breaks indicated with white arrows 


\section{Combined deletion of Xrcc4 and Trp53 via C $11 \mathrm{cre}$ predisposes B cells to lymphomagenesis}

We conducted cohort studies by monitoring two cohorts of $C \gamma 1 C r e X^{c} P^{c}$ mice for the occurrence of B cell lymphomas $\left(X^{c}: X^{c / c}\right.$ or $X^{c /-} ; P^{c}: P^{c / c}$ or $\left.P^{c /-}\right)$. Within the first cohort, we found that $C \gamma 1 C r e X^{c} P^{c /+}$ mice (Additional file 1: Figure $\mathrm{S} 1 \mathrm{~B}, n=19$, blue line) survived normally and were not cancer-prone. This phenotype is similar to that of $\mathrm{CD} 21 \mathrm{CreX}^{\mathrm{c} / \mathrm{-}}$ mice [47] in that both lines only have $\mathrm{Xrcc4}$, but not Trp53, deleted. $\mathrm{C} \gamma 1 \mathrm{CreX} \mathrm{X}^{c /+} P^{c}$ mice (Additional file 1: Figure $\mathrm{S} 1 \mathrm{~B}, n=20$, green line), which still express XRCC4, developed thymic lymphomas or solid tumors. This phenotype is likely due to p53 haploinsufficiency as the genotypes of all the tumors are $P^{c /-}$. In contrast, 11 out of $47 \mathrm{C} \gamma 1 C r e X^{c} P^{c}$ mice succumbed to B lineage lymphoma (Additional file 1: Figure $\mathrm{S} 1 \mathrm{~B}, n=47$, red line) as all 11 tumors expressed $B$ lineage markers including B220 and CD19, while the rest of morbid mice died of thymic lymphomas or solid tumors. The floxed Xrcc4 allele was deleted in all of the B lineage lymphomas but not in thymic lymphomas and solid tumors (data not shown). Within the second cohort, we observed a survival curve closely resembling the first one, with a similar penetrance and latency for tumor development (Fig. 2a), albeit the second cohort included only wt controls $(n=37)$ and $C \gamma 1 C r e X^{c} P^{c}$ mice $(n=51)$. We termed the $C \gamma 1 C r e X^{c} P^{c}$-derived $B$ lineage tumors G1XP lymphomas.

\section{Phenotypic characterization of G1XP lymphomas}

We performed Southern blotting to assay G1XP tumor DNA for Igh rearrangements and found that 7 out of 11 analyzable primary G1XP tumors from the first cohort exhibited clonal Igh rearrangements, along with varying degrees of a germline $\mathrm{J}_{\mathrm{H}}$ band (Additional file 1: Figure S1C). However, the germline band usually occurred in low levels indicating derivation from non-B lineage cells within the tumor. Consistently, the tumor samples analyzed from the second cohort also displayed clonal rearrangements of the $\mathrm{J}_{\mathrm{H}}$ allele (Fig. 2b). Histological analysis of the tumor samples showed that the lymphoma cells possessed diffusely enlarged cytoplasm, salient nuclei, and nucleoli (Fig. 2c), consistent with immunoblastic B cells. Phenotypic characterization of G1XP lymphomas was performed by flow cytometry (Additional file 1: Table S1). We found that all of the lymphoma samples consistently expressed B220, CD24, CD38, CD43, CD93, and CD138. The majority of lymphomas also expressed PNA, a marker for GC B cells (see below), and about $40 \%$ of them were surface IgG positive (Additional file 1: Table S1).

To test whether G1XP lymphomas derived from B cells that had undergone SHM/CSR, we cloned the $\mathrm{VDJ}_{\mathrm{H}}$ exons from three G1XP lymphomas using a PCR approach [47]. We found that G1XP tumors contained
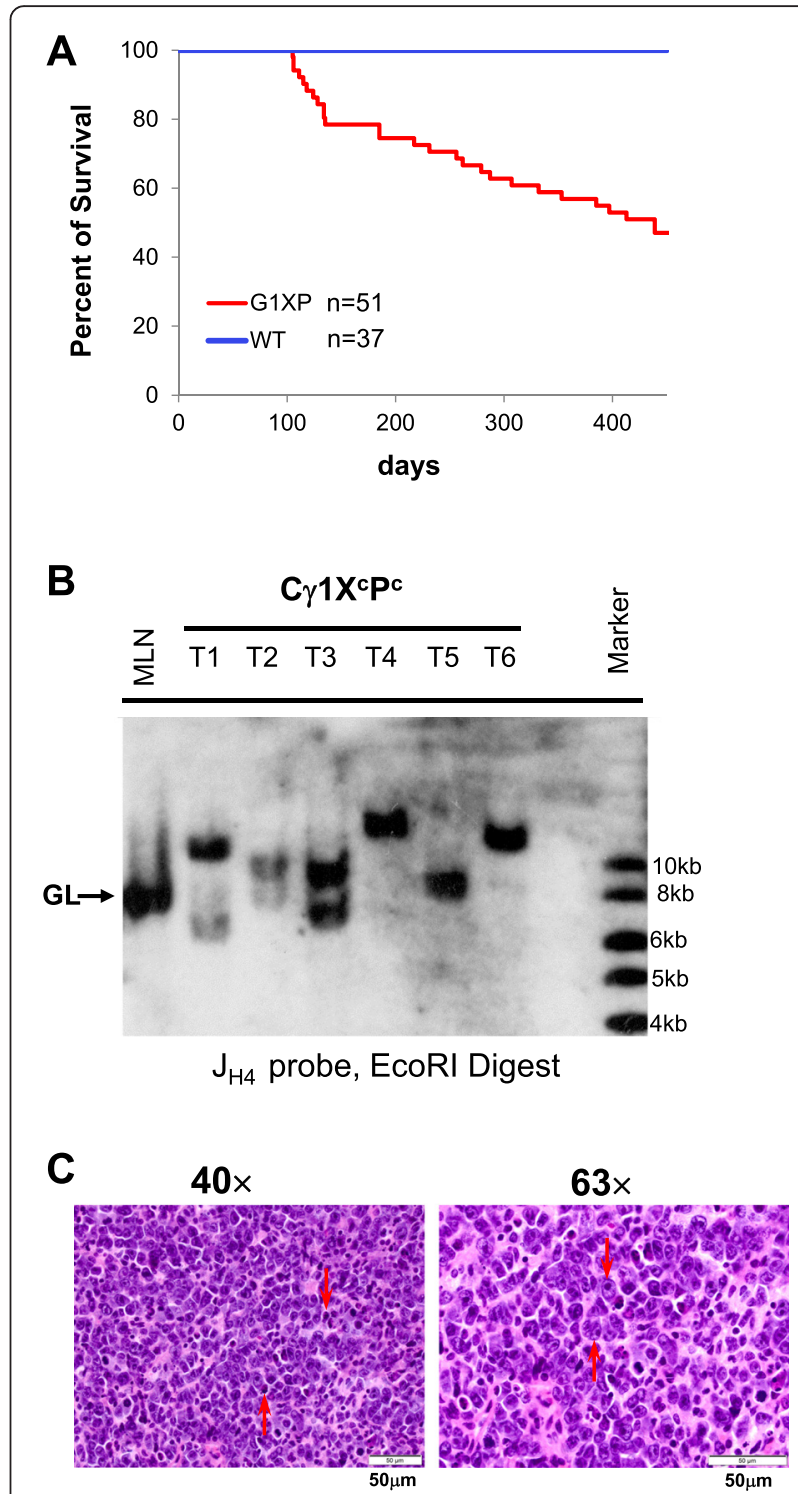

Fig. 2 Establishment of the GIXP B cell lymphoma model. a Kaplan-Meier survival curve: percent survival of wt controls $(n=37)$ and $C y 1 C r e X^{c} P^{c}$ mice $(n=51)$ vs age in days is shown. b Southern Blot analysis of second cohort of $C \gamma 1 C$ reX ${ }^{c} P^{c}$ mice for $J_{H}$ rearrangements. G1XP lymphoma genomic DNA was employed for EcoRl digestion and hybridized with the $\mathrm{J}_{\mathrm{H} 4}$ probe. Germline (GL) bands are indicated (arrow heads). MLN stands for mesenteric lymph node. c H\&E analysis of G1XP lymphomas. Left: a high level of apoptotic cells (red arrows) (objective $\times 40$ ); Right: diffusely enlarged nuclei (red arrow, bottom) and salient nucleoli (red arrow, top) (objective $\times 63$ ). Scale bars $50 \mu \mathrm{m}$

structurally normal in-frame or out-of-frame V(D)J rearrangements; more importantly, we sequenced these $\mathrm{VDJ}_{\mathrm{H}}$ exons and downstream $\mathrm{J}_{\mathrm{H}}$ introns and found that these three tumors harbored 13, 1, and 3 mutations, respectively, in the $\mathrm{J}_{\mathrm{H}}$ regions (Additional file 1: Figure S2). These results further confirm that inactivation of Xrcc4 and Trp53 via Cy1cre leads to B cell lymphomas capable of 
undergoing SHM. Thus, we conclude that the deletion of both $X r c c 4$ and Trp53 genes via CY1Cre results in the development of novel B cell lymphomas.

\section{Analysis of $I g$ loci translocation junctions identifies known and novel translocation partners}

We performed whole genome next generation sequencing (NGS) to identify the inter-chromosomal translocations (CTX) involving $I g$ loci in 6 G1XP lymphomas. NGS allows us to molecularly characterize the CTX junctions at the base pair (bp) level, which may provide insights into the molecular mechanisms leading to these translocations. NGS identified 25 CTXs involving $I g$ genes, 20 of which were confirmed by manual alignment to reference databases $(\mathrm{mm} 9)$, while the remainder was excluded due to alignment artifacts or sequencing limitations. Among the 20 CTXs, 16 of them occurred at the Igh locus, with 10 breakpoints present within or around $\mathrm{S}$ regions on chromosome 12q13.2 (Fig. 3a, Additional file 1: Table S2), indicating that the translocations originated from CSR process; the other 6 CTXs occurred in close proximity to various $\mathrm{V}_{\mathrm{H}}$ gene segments of the Igh locus (Fig. 3a, Additional file 1: Table S2), suggesting that these CTXs were mediated by RAGs. The additional 4 CTXs targeted Igא or $I g \lambda$ loci on chromosome 6 or 16, respectively, with the breakpoints occurring in close proximity to $V \lambda$ or VK gene segments, consistent with RAG-mediated DSBs (Fig. 3a, Additional file 1: Table S2).

Notably, an interesting pattern emerged among these CTXs that apparently separated into two categories. First, all of the 10 CTXs occurring around S or C regions of the Igh locus were translocated to the $c-m y c$ or plasmacytoma variant translocation 1 ( $P v t 1)$ locus on chromosome 15 (8 vs 2 , respectively) (Fig. 3a). The translocation breakpoints at the $c-m y c$ locus clustered in the $5^{\prime}$ non-coding regions on chromosome 15qD1 (Fig. 3b, Additional file 1: Table S2). Second, all of the 10 CTXs occurring close to V gene segments of $I g h, I g K$, and $I g \lambda$ were translocated to various chromosomes involving random genetic or intergenic regions (Fig. 3a) (Additional file 1: Table S2). This intriguing pattern of translocation partners suggests that distinct mechanisms operate to mediate these two categories of translocations, probably involving AID vs RAGs, respectively. NGS data revealed a novel translocation partner of Igh locus, which targeted the Pvt1 locus (Fig. 3c), located about $30 \mathrm{~kb}$ telomeric of the $c-m y c$ locus. The Pvt1 locus contains a long non-coding RNA gene, which is a frequent translocation partner in mouse plasmacytomas and variants of human Burkitt's lymphomas (BL) [50, 51]. NGS data identified Igh breakpoints located within $S \mu$ or $S \alpha$ regions, strongly implicating the involvement of AID (Fig. 3d). The junctional sequences harbored micro-homology $(\mathrm{MH})$, an indicator of alternative end- joining (A-EJ) [35, 52]. Taken together, our data suggest that $I g$ loci translocations are likely caused by AID or RAG activity.

Apart from CTX junctions, we also identified V(D)J recombination junctions from our NGS data. Since Xrcc4 was deleted in the GC B cells, these lymphoma cells harbored normal D-J or V-D-J recombination junctions at the Igh locus (Additional file 1: Figure S3, junction 1 and 2 , respectively). In contrast, we detected aberrant Ig $\lambda$ locus V-J rearrangements, which harbored large deletions of $V \lambda 1$ or $\lambda \lambda 3$ exon including 41 bp of $V \lambda 1$ exon and the entire $J \lambda 3$ exon (Additional file 1: Figure S3, junction 3). These data are consistent with our previous results showing that CD21cre-mediated Xrcc4 deletion led to aberrant $I g \lambda$ rearrangements $[15,47]$. We identified $\mathrm{MH}$ at the V-J junction (Additional file 1: Figure S3, junction 3), consistent with the involvement of A-EJ. Taken together, our data suggest that these aberrant $I g \lambda$ rearrangements occurred in the absence of Xrcc4, probably in the context of secondary $\mathrm{V}(\mathrm{D}) \mathrm{J}$ recombination.

\section{Validation of clonal translocations involving $/ g$ loci in G1XP lymphomas}

To further validate the observed genomic instability, we performed metaphase FISH assay to detect locus-specific clonal translocations, which were also validated via independent methods (Additional file 1: Table S3). Of note, all of the detailed analysis utilized the tumor samples from the second cohort of $\mathrm{C} \gamma 1 \mathrm{CreX} \mathrm{X}^{c} \mathrm{P}^{c}$ mice. Among the six tumors sequenced by NGS, we confirmed that four out of six samples harbored clonal $c-m y c$ translocations while five out of six had Igh locus translocation (Fig. 4a). Clonal translocations were defined as more than $80 \%$ of tumor metaphases harboring such translocations. Furthermore, we found that six out of nine analyzed G1XP lymphoma samples harbored clonal $c$-myc translocations while seven out of nine contained clonal Igh translocations. Next, we performed FISH analysis using 3'Igh (red) and $3{ }^{\prime} \mathrm{c}-\mathrm{myc}$ (green) probes or $5^{\prime} \mathrm{c}$-myc (red) and 5 'Igh probes (green) to determine whether these are reciprocal translocations occurring between Igh and $c-m y c$ loci. Indeed, we found that $I g h$ and $c-m y c$ probes were juxtaposed on the translocated chromosomes (Fig. 4b). Thus, we conclude that the majority of G1XP lymphomas harbor Igh-c-myc reciprocal translocations. In addition to these translocations, we detected clonal translocations involving the $I g \lambda$ locus (Additional file 1: Figure S4), one of the Ig light chain gene loci, in the majority of G1XP lymphomas analyzed.

Interestingly, we identified a clonal $\operatorname{Igh}$ translocation in one G1XP lymphoma that did not involve $c$-myc locus since $c-m y c$ FISH probes had intact signals (Fig. 4c). Notably, this particular G1XP lymphoma (119 J) is aneuploid as evidenced by five copies of broken Igh locus 


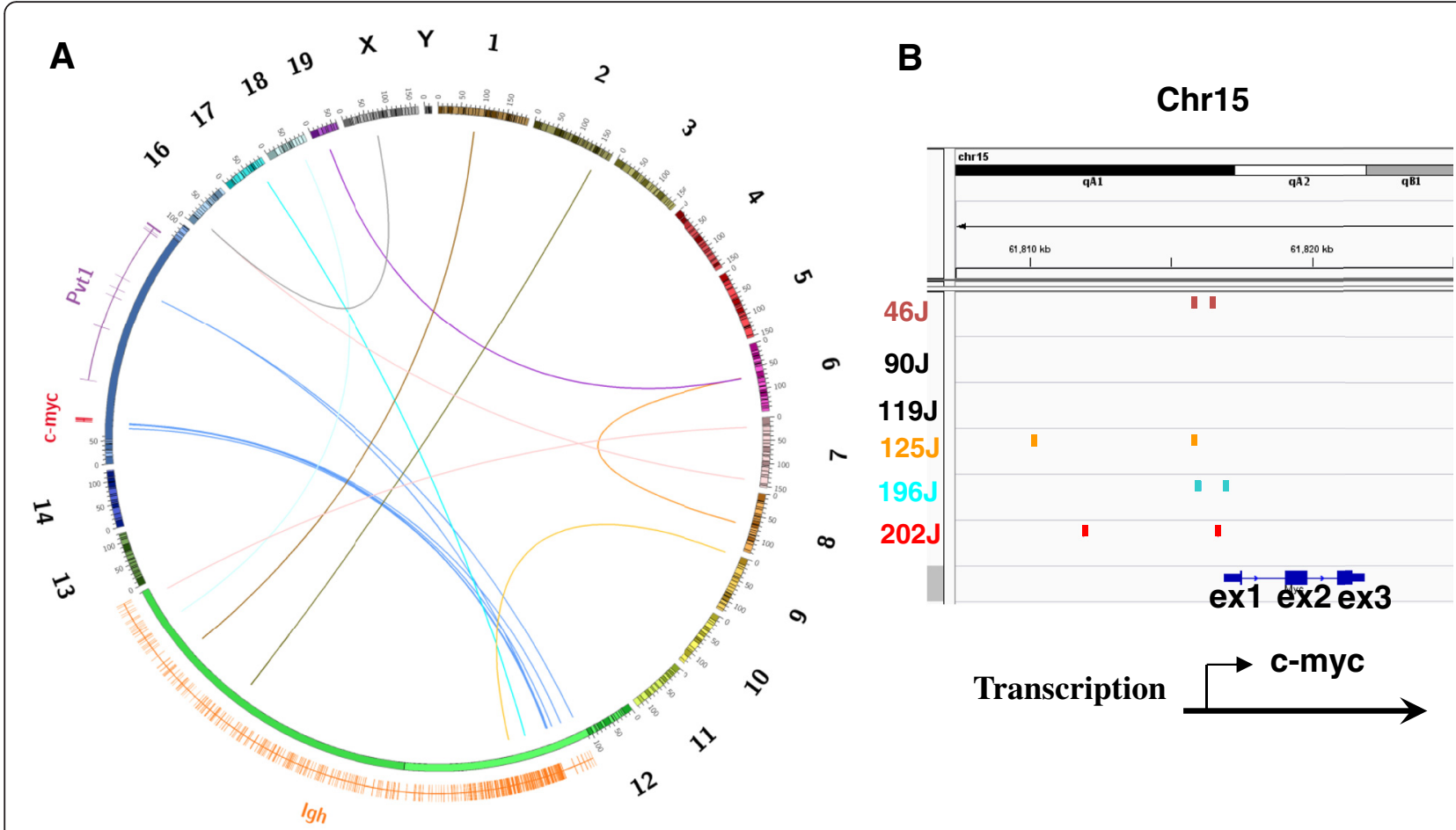

C Chr15

Pvt1

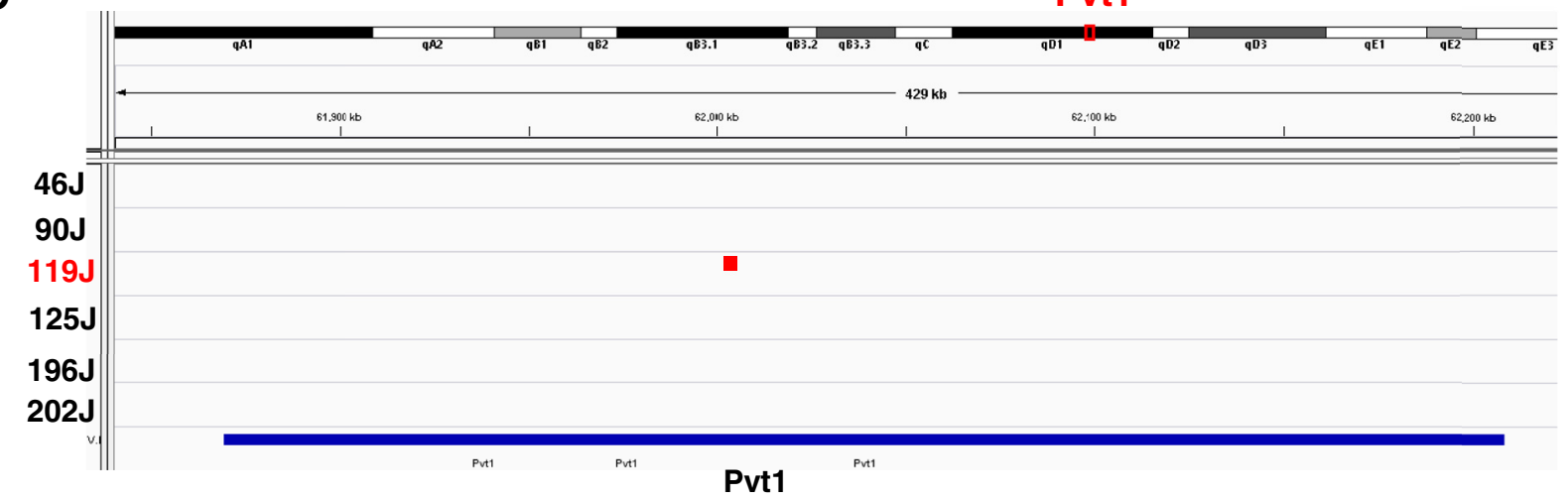

D Junction 1-119J-CTX-chr12 114662370 - chr15 62002785

chr15:62002697-62002882 Pvt1 locus

GCTTGTAACTACCAAGCACTGGGATAGCAAACACTCACCATGGTAAGAATTAACCCAGTTCTCTAAGAAAGCTCCTTACTAAGCAGGAGGATCAATGAGT CTTGCTCAGCTGACCCCAGCTCAGCTCACACAGCTCACCATGGTAAGAATTAACCCAGTTCTCTAAGAAAGCTCCTTACTAAGCAGGAGGATCAATGAGT CTTGCTCAGCTGACCCCAGCTCAGCTCACACAGCTCAGTTCAATCCAGCTCCGCTCACCACAGCTCATCCCAGTTTACCCCAGTTCAGCTCATCTTACCC chr12:114662272-114662457 (within $S \mu$ of Igh locus)

\section{Junction 2-119J-CTX-chr12 114499669 - chr15 62002643}

chr15:62002550-62002733 Pvt1 locus

AAAGCAAAGATGCTTGTTTAGGTTTGTGTTTCTGGGCTTTGGGAAGTTAGTTCATGGTTGGGCAACTGCATCTGCCTTACAATATGGCAGAAGTCGGAAGG AAAGCAAAGATGCTTGTTTAGGTTTGTGTTTCTGTGCTGAGTTAGTCTGGGCTAGGCTGAGTTAGTCTAGGCTGGACCAAATTAGGCTGGATGGGCTAAAC GTTAGTCTGGGCTAGGCTGAGTTAGTCTGGACTAGGCTGAGTTAGTCTGGGCTAGGCTGAGTTAGTCTAGGCTGGACCAAGTTAGGCTGGATGGGCTAAAC chr12:114499573-114499763 (within S $\alpha$ of Igh locus)

Fig. 3 (See legend on next page.) 
(See figure on previous page.)

Fig. 3 Analysis of CTX junctions identifies known and novel translocation partners. a A Circos plot depicts all CTXs involving Igh, Igk, and Igג loci. Individual chromosomes are shown as color-coded bars with specific banding patterns. The region on chr12 (in green) $(114,480,000-117,249,000$ ) is zoomed in $\times 400$ including the Igh locus while the region on chr15 (in blue) $(61,800,000-62,083,000)$ is zoomed in $\times 1600$ including c-myc and Pvt1 loci. All Igh CTXs involving S or C regions are translocated to c-myc or Pvt1 locus shown as a cluster of blue lines. All other lg CTXs involving $\checkmark$ gene segments are translocated to various chromosomes shown as different color-coded lines. $\mathbf{b}$ The view within the IGV browser shows all the CTX breakpoints occurring upstream of or within c-myc 1st exon. c The location of Pvt1 translocations shown in the IGV browser. $\mathbf{d}$ Analysis of junction sequences of the lgh-Pvt1 translocation. Sequences from NGS are aligned with genomic sequences of mm9 with chr15 sequence in black and chr12 sequence in blue. Micro-homology at the junctions is in red and underlined

and five copies of intact $c-m y c$ locus (Fig. 4c), suggesting the existence of novel translocation partners. Indeed, NGS data showed that this particular lymphoma harbored an Igh-Pvt1 translocation (Fig. 3d). Next, we performed FISH analysis to validate the occurrence of this translocation. Surprisingly, we found that almost all metaphases harbored an intact Pvt1 locus with $5^{\prime}$ and 3' Pvt1 probes always co-localized (Fig. 5a, left panel, and 5b), suggesting the absence of gross chromosomal structural alterations at the Pvt1 locus. To reconcile the apparent discrepancy between NGS and FISH data, we used the 3' Igh and $3^{\prime} P v t 1$ probes for FISH assay and found that these two probes co-localized in $100 \%$ of metaphases analyzed (Fig. 5a, middle panel and 5b). In contrast, the $5^{\prime} I g h$ and $5^{\prime} P v t 1$ probes were not co-localized (Fig. 5a, right panel, and $5 \mathrm{~b})$. Thus, these data demonstrated that a piece of chromosome 12 was inserted into the Pvt1 locus, which contained the centromeric portion of the Igh locus encompassing the region from $\mathrm{S} \alpha$ to $\mathrm{S} \mu$ (Fig. 5c). More importantly, these data implicate that G1XP lymphomas harbor complicated genomes including segmental translocations.

\section{G1XP lymphomas harbor ongoing DNA damage and a high level of clonal heterogeneity}

We hypothesize that G1XP lymphomas probably harbor ongoing genomic instability that mediates the acquisition of chromosomal structural rearrangements. To test this hypothesis, we examined the DNA damage level in G1XP lymphomas via detecting the phosphorylation of H2AX (at Ser 139), a variant of H2A. H2AX phosphorylation occurs at sites flanking DSBs minutes after their induction, leading to the formation of distinct gammaH2AX foci $(\gamma-\mathrm{H} 2 \mathrm{AX})$ [53]. Thus, $\gamma-\mathrm{H} 2 \mathrm{AX}$ foci reflect the level of ongoing DSBs and are often used as an indicator of DSB formation. We used a flow cytometrybased method to measure $\gamma-\mathrm{H} 2 \mathrm{AX}$ level in the G1XP lymphomas and in wt naïve $\left(\mathrm{B}_{2} 20^{+} \mathrm{PNA}^{\text {low }}\right)$ and GC $\left(\mathrm{B}_{220}{ }^{+} \mathrm{PNA}^{\text {high }}\right) \mathrm{B}$ cells as controls. Our data showed that G1XP lymphoma cells displayed a remarkably high level of $\gamma$-H2AX staining (Fig. 6a, right panel). In addition, this particular lymphoma expressed the GC B cell marker, PNA (Fig. 6a, left panel). In contrast, both the wt naïve and GC B cells exhibited a minimal level of
$\gamma$-H2AX staining (Fig. 6b). Notably, the $\gamma-\mathrm{H} 2 \mathrm{AX}$ level is consistently higher in GC B cells than naïve $B$ cells (Fig. 6b). Thus, we conclude that G1XP lymphomas harbor ongoing DNA damage.

We predict that G1XP lymphomas may display a higher level of clonal heterogeneity. To test this possibility, we employed FISH assays to further analyze the lymphomas harboring the $c-m y c$ translocation in detail. Our analysis of these lymphomas showed that all metaphases indeed contained a $c-m y c$ translocation as shown by the split signals of $5^{\prime}$ and $3^{\prime} c-m y c$ probes. Unexpectedly, we found that the configuration of FISH signals was highly heterogeneous since we observed an array of configurations that showed various numbers of intact, green (G) only or red (R) only FISH signals (Fig. 7a). It appeared that there were a few dominant subclones, for example, clone $(1,3,2)$ and clone $(2,2,2)$ (intact, G only, R only) (Fig. $7 b$ ), which occurred at a relatively high frequency, and many minor subclones carried various configurations of FISH signals (Fig. 7a). Thus, our G1XP lymphomas may provide a unique and novel model to study the mechanism of ongoing genomic instability and clonal heterogeneity.

\section{Discussion}

A high level of genomic complexity and clonal heterogeneity may contribute to relapse or therapy resistance [54, 55]; however, key determinants regulating their generation have not been clearly addressed. In the current study, we establish a unique lymphoma model by specifically deleting Xrcc4 and Trp53 in the subset of $\mathrm{B}$ cells proposed to be prone to lymphomagenesis, namely, GC B cells [1]. Our mutant mouse B cells spontaneously develop B cell lymphomas, and we employed multiple approaches to characterize their genomic instability. Our studies reveal several important discoveries: (1) Ig loci translocations can be attributed to distinct mechanisms including AID- or RAGassociated DSBs in mature B cells; (2) AID-associated Igh translocations target oncogenes such as $c$-myc whereas RAG-associated translocations appear to involve random genomic loci; and (3) G1XP lymphomas harbor complicated genomes including segmental translocations, and exhibit a high level of ongoing DNA damage and clonal heterogeneity. Taken together, we propose that 


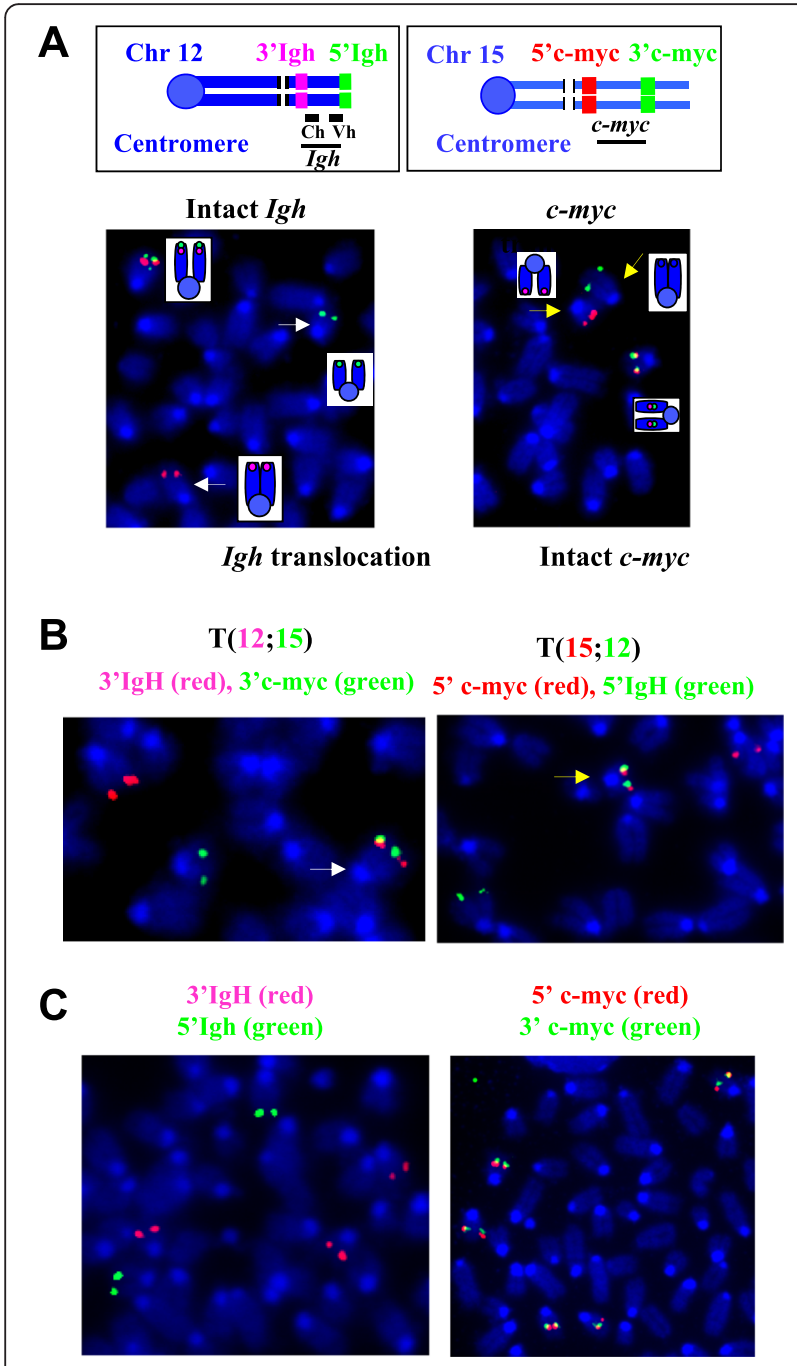

Fig. 4 FISH validation of Igh locus translocations. $\mathbf{a}$, b Inactivation of Xrcc4 and Trp53 via CY1-cre leads to reciprocal Igh-c-myc translocation in G1XP lymphoma (46 J). a Upper left: Diagram of Igh FISH probes. Bottom left: An example of metaphase Igh FISH image. An intact Igh shows co-localized red and green signals while a translocated locus appears as split red and green signals on different chromosomes (white arrow). Upper right: Diagram of c-myc FISH probes. Bottom right: An example of metaphase FISH showing c-myc locus translocation (yellow arrow) and an intact c-myc locus. b Left: A metaphase FISH image showing the $\mathrm{t}(12 ; 15)$ translocation with $3^{\prime}$ Igh (red) and $3^{\prime} \mathrm{c}-$-myc (green) probes juxtaposed on the derivative chr12 (white arrow). Right: A metaphase FISH image showing the $t(15 ; 12)$ translocation with $5^{\prime} \mathrm{c}-$ myc (red) and $5^{\prime}$ Igh (green) probes juxtaposed on the derivative chr15 (yellow arrow). A normal chr12 and chr15 are also present in the metaphase. c Left: a metaphase FISH image showing the Igh locus translocations in G1XP lymphoma (119 J) with $3^{\prime}$ and $5^{\prime}$ lgh probes split. Right: a metaphase FISH image showing the intact c-myc locus with $3^{\prime}$ and $5^{\prime}$ probes co-localized in the same lymphoma sample

combined NHEJ and p53 defects may serve as an underlying mechanism for a high level of genomic complexity and clonal heterogeneity in cancers.
The NHEJ and p53 deficiency models have made significant contributions to our understanding of translocation and lymphomagenesis, more importantly, the molecular mechanism of DNA repair [15, 37, 39-43, 47]. Emerging evidence suggests that defects in DSB repair can lead to oncogenic genomic instability and, in support of this notion, mutations in DNA break repair factors are implicated in a number of human tumors, including breast, colon, and lung cancers [56]. In addition, somatic mutations in NHEJ factors have been identified in different types of human tumors including hypomorphic mutations of Artemis in EBV-associated lymphomas [57], mutations of Lig4 or XLF associated with non-Hodgkin's diffuse large B cell lymphoma [58-60], and mutations of DNA-PKcs in glioblastoma and lung cancer [56]. TP53 mutations were associated with human $\mathrm{BL}$, its leukemic counterpart L3-type B cell acute lymphoblastic leukemia, B cell chronic lymphocytic leukemia (CLL), and, in particular, its stage of progression known as Richter's transformation [61]. Richter syndrome (RS) is characterized by the transformation of CLL to high-grade non-Hodgkin's lymphoma. Consistently, a recent study by performing a comprehensive molecular characterization of 86 pathologically proven RS reveals that TP53 disruption (47.1\%) and $c-m y c$ abnormalities (26.2 \%) were the most frequent alterations in RS [62], both of which are present in our models. Therefore, it is likely that defects in both NHEJ and p53 or in the modulators of these pathways may contribute to the development of human lymphomas, at least, a subset of them.

Our NGS data identified Igh translocation partners, $c-m y c$ and $P v t-1$, which are often observed in $\mathrm{BL}$ and a subset of diffuse large B cell lymphomas [51, 63-67]. Thus, our model might provide a unique platform to better elucidate the molecular mechanisms of translocations in B cell lymphomagenesis. Prior studies demonstrate an important role of AID in promoting translocations in B cells [30]. We and others also prove that the NHEJ deficiency-induced Igh locus instability [15] or the generation of Igh-c-myc translocation is completely dependent on AID [68]. Consistently, we found that the majority of Igh translocations in G1XP lymphomas probably originated from AID-initiated DSBs, further solidifying its role in inducing Igh locus genomic instability. Furthermore, we find that half of $I g$ translocations occur in close proximity to $\mathrm{V}$ gene segments in the $I g h, I g \kappa$, or $I g \lambda$ locus, strongly implicating these translocations catalyzed by RAGs. Notably, the partners of these $I g \mathrm{~V}$ gene translocations are random genetic loci or intergenic regions scattered all over the genome. We suggest that the generation of such translocations probably is largely influenced by mechanistic factors [69], such as the increased frequency of RAGmediated DSBs at the Igh or Igl locus in the context of 


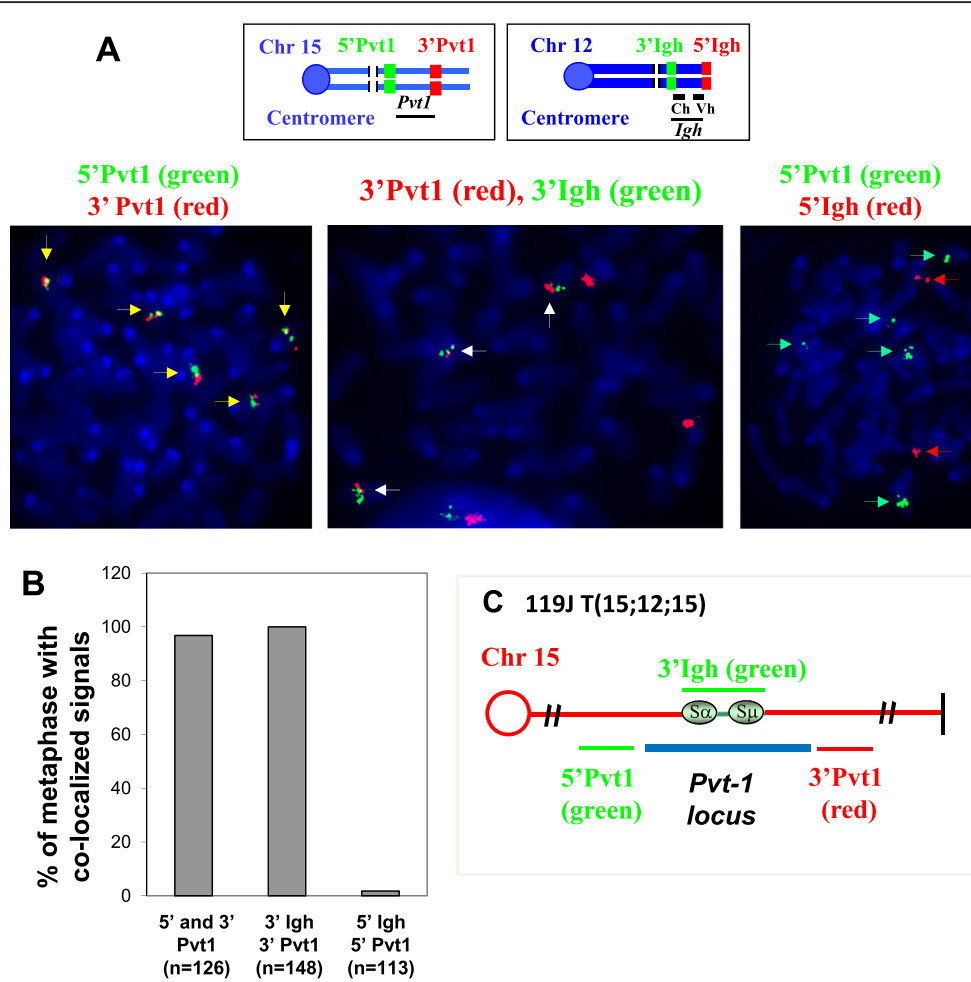

Fig. 5 G1XP lymphomas harbor segmental translocations involving Pvt1 locus. a Metaphase FISH analysis of the lgh-Pvt1 translocation in G1XP lymphoma (119 J). Top: Diagrams of Igh or Pvt1 FISH probes. Bottom left: five copies of the 5' (green) and 3' (red) Pvt1 probes are co-localized (yellow arrows); Bottom middle: three copies of the $3^{\prime} \mathrm{Igh}$ (green) and $3^{\prime}$ Pvt1 probes are co-localized (white arrows); Bottom right: five copies of $5^{\prime}$ Pvt1 probe (green) and two copies of 5' Igh probe (red) are not co-localized (indicated by green or red arrows, respectively). b Quantification of Igh-Pvt1 translocations analysis in G1XP lymphoma (119 J). The number of analyzed metaphases is indicated. c Schematic map of $\mathrm{t}(15 ; 12 ; 15)$ translocation in G1XP $119 \mathrm{~J}$. Chr15 is in red and the Pvt1 locus is depicted in blue line with the $5^{\prime}$ and $3^{\prime}$ flanking FISH probes indicated. The inserted region of Chr12 is in green encompassing the region from Sa (junction 2) to Su (junction 1) as shown in Fig. 3d. The breakpoints of Pvt1 locus are adjacent to each other in these two CTX junctions with only 143 bp deleted in the Pvt 1 locus

secondary $\mathrm{V}(\mathrm{D}) \mathrm{J}$ recombination. In this regard, these results are consistent with our previous findings that a small percentage of peripheral B cells harbor RAG-dependent $I g \lambda$ breaks/translocations in the absence of Xrcc4 [15]. Thus, our conclusion is further corroborated that mature B lymphocytes can undergo secondary $\mathrm{V}(\mathrm{D}) \mathrm{J}$ recombination, which may contribute to mature $\mathrm{B}$ cell lymphomagenesis.

Our data reveal that Trp53 deficiency is essential to cause B cell lymphomas; however, Trp53 deficiency per se does not increase the level of DSBs markedly. Thus, we propose that $\operatorname{Trp} 53$ deficiency enhances the tolerance threshold of B cells for genomic instability induced by DNA repair deficiency in our model, thereby predisposing to lymphomagenesis. Consistent with our hypothesis, it has been shown that, in response to DSBs, p53 is phosphorylated and activated by ATM [70], then monitors DSBs in the context of G1 checkpoints, and signals arrest and/or apoptosis [71]. Trp53 deficient mice usually succumb to thymic lymphomas that are aneuploid but lack translocations
[72-75]. Of note, CD21cre-mediated deletion of Trp53 in peripheral B cells results in the development of mature B cell lymphomas $\left(\operatorname{IgM}^{+}\right)$that lack recurrent clonal translocations involving $I g$ or $c-m y c$ loci [76]. Overall, these findings support our hypothesis that Trp53 deficiency enables B cells to tolerate genomic instability. Furthermore, we propose that the regulation of genomic instability tolerance is more p53-dependent in $B$ cells than in other cell lineages. This notion is supported by the findings that NHEJ/p53 germline deficient mice developed only pro-B cell lymphomas $[39,43]$. Thus, our unique mouse model may facilitate the discovery of critical components of p53mediated effector cascades that regulate genomic instability tolerance. Furthermore, we were able to establish cell lines from our lymphoma model (data not shown), which would facilitate subsequent studies. Addressing these fundamental questions potentially identifies targets that specifically attack cancer cells with unstable genomes, while leaving genetically stable normal cells unaffected. 

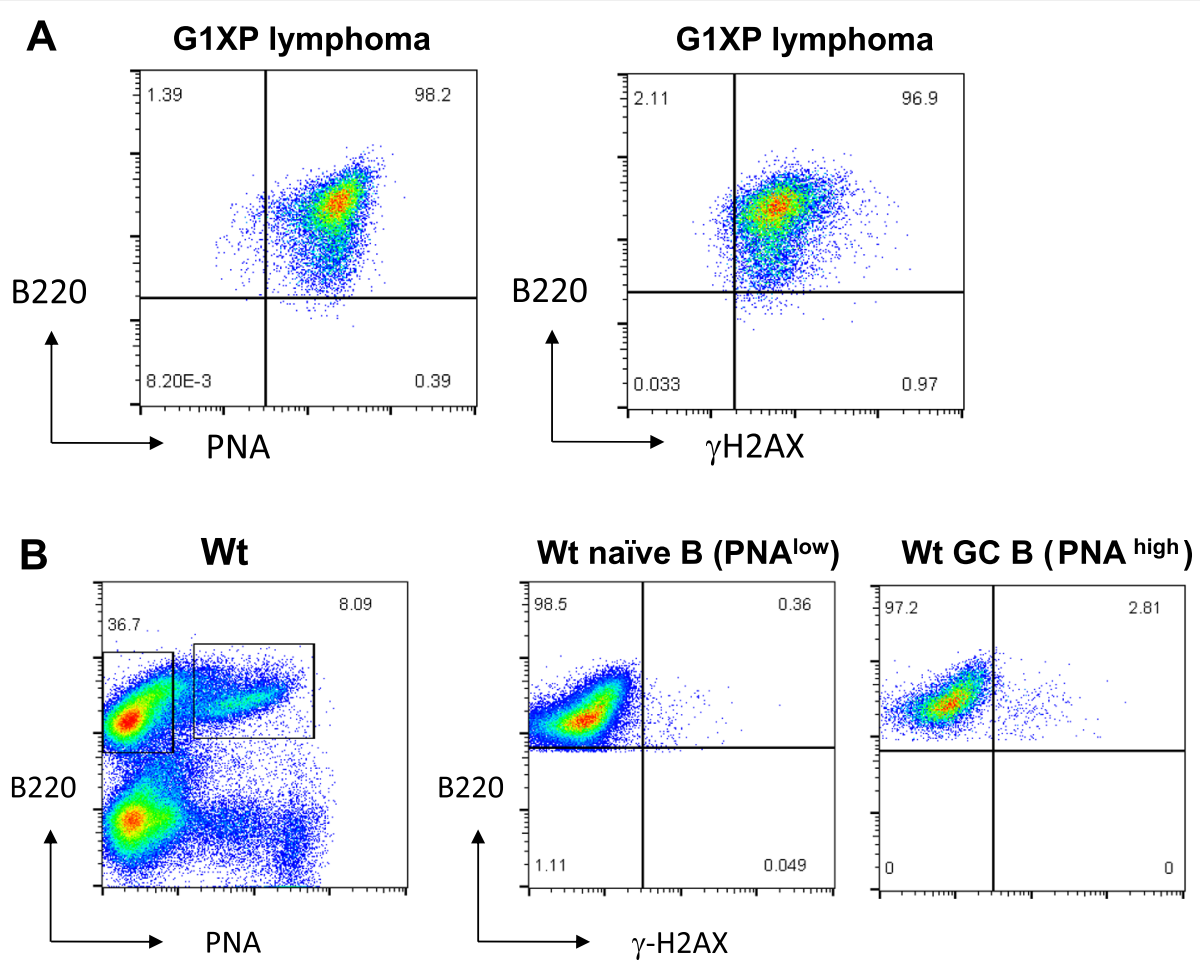

Fig. 6 G1XP lymphomas harbor ongoing DNA damage. a FACS analysis of a GC B cell marker, PNA (left panel) and Y-H2AX foci staining (right panel) for G1XP lymphomas ( $n=3$ per group). b Wt splenocytes were isolated from immunized mice and stained for GC B cell markers, B220 and PNA. The

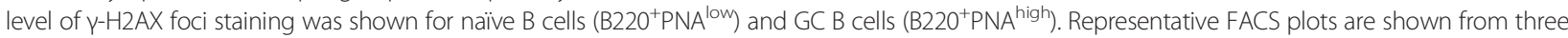
independent experiments using independent tumor samples

With regard to the potential of our model in clinical applications, such as biomarkers for diagnosis and therapy [77], we suggest that our unique model might potentially provide novel insights into the biomarker development in predicting the onset of the B cell lymphomas, given that this lymphoma model has a relatively long latency and low penetrance. In addition, novel therapies have been developed rapidly to treat B cell lymphomas or CLL, for example, Ibrutinib and new agents are effective for TP53 mutant lymphoma cells; thus, there is the potential of clinical applications of our lymphoma model for testing new agents [78-80]. Mechanistically, it would be of interest to elucidate which signaling pathway is required for the survival of these lymphoma cells.

\section{Conclusions}

Deletion of $\mathrm{Xrcc4}$ and Trp53 via $\mathrm{C} \gamma 1 \mathrm{Cre}$ leads to novel $B$ cell lymphomas that appear to derive from GC B cells. These B cell lymphomas harbor ongoing DNA damage and exhibit a high level of clonal heterogeneity for characteristic $c-m y c$ translocations. We propose that combined NHEJ and p53 defects may serve as an underlying mechanism for a high level of genomic complexity and clonal heterogeneity in cancers.

\section{Methods}

Generation of mouse models

C 1 1Cre knock-in (KI) mice [49], Xrcc4 [37], or Trp53 [81] conditional knock-out (KO) mice were generated previously. These mice were in mixed genetic background of C57BL/6, 129/Ola, and FVB/N [37, 49, 81]. Animal work was approved by the Institutional Animal Care and Use Committee of University of Colorado Anschutz Medical Campus (Aurora, CO), National Jewish Health (Denver, CO), and Children's Hospital in Boston (Boston, MA).

\section{B cell culture, FISH, and Southern Blot analysis}

Splenic B cells were isolated from naïve mice, purified by negative selection kit (Stem Cell Technologies, Canada), activated with anti-CD40 and IL4 as described previously [82], and collected 4 days after culture for metaphase preparation and FISH analysis. FISH analysis was performed with specific BAC probes as previously described [82] (see details in Additional file 1). Genomic DNA was isolated from tumor masses or normal tissues from control mice, and Southern blotting was performed as previously described [41]. 
A

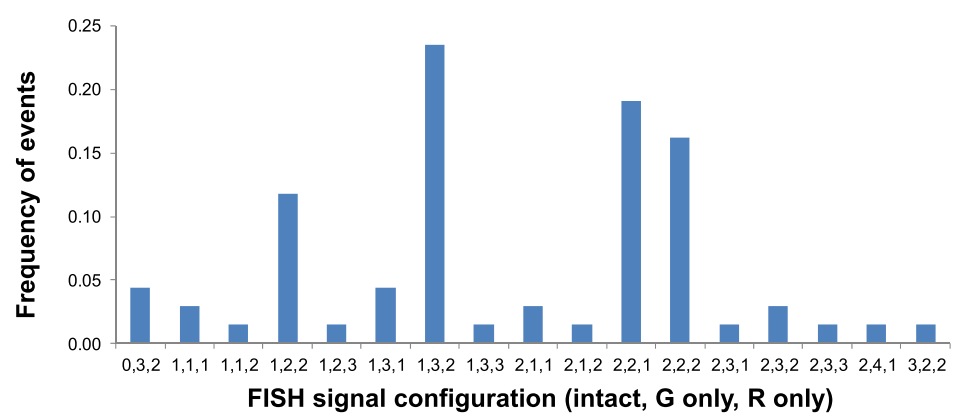

B

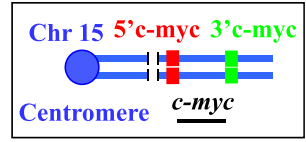

$(1,3,2)$

Intact, G only, R Only
$(2,2,2)$

Intact, G only, R Only

Fig. 7 G1XP lymphomas harbor a high level of clonal heterogeneity. a Quantification of c-myc translocations in G1XP lymphoma samples ( $n=3$ independent tumor samples) analyzed by metaphase FISH. We subdivide the configuration of FISH signals into three categories: Intact: green and red probes co-localized; G only: green probe only ( $3^{\prime}$ c-myc), R only: red probe only ( $5^{\prime} \mathrm{c}-\mathrm{myc}$ ). The frequency of different configurations of FISH signals was shown from one representative sample, and at least 150 metaphases were analyzed in total for each sample. b Top: Diagram of c-myc FISH probes. Bottom: Representative c-myc translocations showing different configurations of FISH signals. Numbers in parenthesis indicate the number of FISH signals for each category. Intact: yellow arrows; G only: green arrows; R only: red arrows

\section{H\&E staining, flow cytometry, and H2AX foci staining} Tumor masses usually presented in the abdomen and were adjacent to gut-associated lymphoid tissues such as mesenteric lymph nodes or Peyer's patch. Tumors were dissected, fixed in $10 \%$ formalin, and processed for H\&E histology staining. Tumor single-cell suspensions were prepared and subjected to flow cytometry for phenotypic characterization. Samples were analyzed using a FACSCalibur (BD Bioscience), and FACS analysis was performed with FlowJo software. Single-cell suspensions prepared from tumors or wt naïve or GC B cells were stained for $\gamma$-H2AX foci according to the manufacturer's instructions (BD Bioscience). The generation of splenic GC B cells was induced by in vivo immunization as described previously [82].

NGS library preparation, sequencing platform, and data analysis

Tumor DNA samples were employed to generate the NGS paired-end library using the standard TruSeq DNA library preparation kit (Illumina, San Diego, CA). The libraries were subjected to whole genome sequencing on the Illumina Hi-Seq 2000 platform (pair-ended, $2 \times 100 \mathrm{bp}$ per read). Details of NGS analysis are provided in the Additional file 1 including usage of CREST software [83] and generation of Circos plots [84].

\section{Additional files}

Additional file 1: Figure S1. Establishment of G1XP lymphoma model. (A) Specific Xrcc4 deletion via CY1Cre in GC B cells. PCR analysis of genomic DNA isolated from bone marrow (BM), thymus, sorted naïve B cells (B220+PNAlow), and GC B cells (B220+PNAhigh) of immunized

$\mathrm{C} \gamma 1 \mathrm{Cre} \mathrm{Kl}$ or $\mathrm{C} \gamma 1 \mathrm{CreX} /+$ mice. The middle band is non-specific amplification of PCR reaction for BM, thymus and B220+PNAlow B cells. GC B cells (B220+PNAhigh) show the complete deletion of Xrcc4 floxed allele. Splenocytes were stained using anti-B220 and anti-PNA antibodies. (B) Kaplan Meier survival curve of the first cohort of mice including $\mathrm{C}_{\mathrm{T}} 1 \mathrm{CreX} \mathrm{CPC} /$ + mice $(n=19$, blue line), $C \gamma 1 \mathrm{CreX} /+P c$ mice $(n=20$, green line) and CY1CreXCPC mice ( $n=47$, red line). (C) Southern Blot analysis of 1st cohort of $\mathrm{C} Y 1 \mathrm{CreXCPC}$ mice. G1XP lymphomas harbor clonal JH rearrangements. Southern blot analyses for $\mathrm{JH}$ rearrangements in G1XP lymphoma genomic DNA employing EcoRI digestion and the JH4 probe. Germline (GL) bands are indicated (arrow heads). Asterisks (*) indicate rearranged $\mathrm{JH}$ locus in lymphoma DNA. MLN stands for mesenteric lymph node. Figure 
S2. G1XP lymphomas harbor somatic hypermutations. Germline sequences from either the $\mathrm{JH} 1-4$ or $\mathrm{JH} 3-4$ region were aligned with G1XP lymphoma sequences. The mismatched sequences (in red font) at the beginning of the sequences are derived from rearranged VD or D regions. To exclude the effects of $V(D) J$ recombination in sequence diversity, we only identified the mutations in $\mathrm{JH}$ exon or intron regions that could be unequivocally aligned to the germline sequences. The rearranged JH exon regions are underlined for each individual G1XP lymphoma samples, and the mutations are marked with "*". Figure S3. G1XP lymphomas harbor normal or aberrant V(D)J recombination junctions. NGS data showed the presence of normal D-J (junction 1) and V-D-J (junction 2) junctions at the Igh locus or aberrant V-J junction (junction 3) at $\lg \lambda$ locus.V, D, and J exons were labeled and depicted as orange bars.MH: micro-homology. Figure S4.Clonal Ig $\lambda$ translocations in G1XP lymphoma. Top: schematics of Ig locus on chromosome 16. Bottom: Metaphases from G1XP lymphoma samples were analyzed by FISH for hybridization to $\lg \lambda$ probes as indicated in the schematics. Representative Ig $\lambda$ translocations in G1XP lymphomas are shown. Table S1. Phenotypic characterization of G1XP lymphoma via flow cytometry. Table S2. Summary of translocation involved Igh and Igl genes. Table S3.Validation of Translocations by PCR, Sanger Sequencing or FISH.(PDF 1221 kb)

\section{Competing interests}

The authors declare that they have no competing interests.

\section{Authors' contributions}

JHW and ZC designed the study and wrote the paper. JHW, ZC, and SSV established the mouse cohorts, monitored the survival, and collected the tumor samples for NGS and FACS analysis. JHW, ZC, MTE, and SSV contributed to the metaphase FISH analysis of primary B cells and lymphoma samples. KG, SL, and $\mathrm{KJ}$ analyzed the NGS sequencing data. KG performed the Circo plot analysis. SL employed the IGV software to identify the translocation locations. JHW, MTE, and MR manually aligned the translocation junction sequences. JHW and MTE performed the $\mathrm{YH} 2 \mathrm{AX}$ foci staining. MDE provided the technical assistance for FISH acquisition, analysis, and sequence alignment. All authors read and approved the final manuscript.

\section{Acknowledgements}

We thank Drs. Frederick W. Alt for his generous support of this study and Ryan T. Phan for his contribution to the model. We thank Drs. Klaus Rajewsky for the $\mathrm{C} \gamma 1 \mathrm{Cre} \mathrm{KI}$ mice and Xiayuan Liang and Zenggang Pan for the histology analysis. We thank Dr. Roberta Pelanda for the critical reading of the manuscript. NGS experiments were performed by the Genomics and Microarray Core Facility at University of Colorado Anschutz Medical Campus. This work was supported by the University of Colorado School of Medicine and Cancer Center startup funds, a Boettcher Foundation Webb-Waring Biomedical Research Award, an American Society of Hematology Scholar Award, a fund from Cancer League of Colorado, NIH-R21CA184707, and $\mathrm{NIH}-\mathrm{R01CA} 166325$ to JHW and MTE is supported by NIH-3R01CA1663250251.

\section{Author details}

'Department of Immunology and Microbiology, University of Colorado, Anschutz Medical Campus, 12800 E. 19th Ave, Mail Stop 8333, Aurora, CO 80045, USA. ${ }^{2}$ Department of Biomedical Research, National Jewish Health, Denver, CO 80206, USA. ${ }^{3}$ Integrated Center for Genes, Environment and Health, National Jewish Health, Denver, CO 80206, USA. ${ }^{4}$ Department of Biochemistry and Molecular Genetics, University of Colorado, Anschutz Medical Campus, Aurora, CO 80045, USA.

\section{Received: 6 November 2015 Accepted: 28 December 2015} Published online: 07 January 2016

\section{References}

1. Kuppers R. Mechanisms of B-cell lymphoma pathogenesis. Nat Rev Cancer. 2005;5(4):251-62.

2. Alt FW, Zhang Y, Meng FL, Guo C, Schwer B. Mechanisms of programmed DNA lesions and genomic instability in the immune system. Cell. 2013;152(3):417-29.
3. Nussenzweig A, Nussenzweig MC. Origin of chromosomal translocations in lymphoid cancer. Cell. 2010;141(1):27-38.

4. Bassing $\mathrm{CH}$, Swat W, Alt FW. The mechanism and regulation of chromosomal V(D)J recombination. Cell. 2002;109(Suppl):S45-55.

5. Dudley DD, Chaudhuri J, Bassing CH, Alt FW. Mechanism and control of $V(D) J$ recombination versus class switch recombination: similarities and differences. Adv Immunol. 2005;86:43-112.

6. Jung $D$, Alt FW. Unraveling V(D)J recombination: insights into gene regulation. Cell. 2004;116(2):299-311.

7. Rooney S, Chaudhuri J, Alt FW. The role of the non-homologous end-joining pathway in lymphocyte development. Immunol Rev. 2004;200:115-31.

8. Gay D, Saunders T, Camper S, Weigert M. Receptor editing: an approach by autoreactive B cells to escape tolerance. J Exp Med. 1993;177(4):999-1008.

9. Jankovic M, Casellas R, Yannoutsos N, Wardemann H, Nussenzweig MC. RAGs and regulation of autoantibodies. Annu Rev Immunol. 2004;22:485-501.

10. Nemazee D. Receptor editing in lymphocyte development and central tolerance. Nat Rev Immunol. 2006;6(10):728-40.

11. Pelanda R, Schwers S, Sonoda E, Torres RM, Nemazee D, Rajewsky K. Receptor editing in a transgenic mouse model: site, efficiency, and role in B cell tolerance and antibody diversification. Immunity. 1997;7(6):765-75.

12. Tiegs SL, Russell DM, Nemazee D. Receptor editing in self-reactive bone marrow B cells. J Exp Med. 1993;177(4):1009-20.

13. Monroe RJ, Seidl KJ, Gaertner F, Han S, Chen F, Sekiguchi J, et al. RAG2:GFP knockin mice reveal novel aspects of RAG2 expression in primary and peripheral lymphoid tissues. Immunity. 1999;11(2):201-12.

14. Yu W, Nagaoka H, Jankovic M, Misulovin Z, Suh H, Rolink A, et al. Continued RAG expression in late stages of B cell development and no apparent re-induction after immunization. Nature. 1999:400(6745):682-7.

15. Wang JH, Gostissa M, Yan CT, Goff P, Hickernell T, Hansen E, et al. Mechanisms promoting translocations in editing and switching peripheral $\mathrm{B}$ cells. Nature. 2009;460(7252):231-6.

16. Brandt $\mathrm{VL}$, Roth $\mathrm{DB}$. Recent insights into the formation of RAG-induced chromosomal translocations. Adv Exp Med Biol. 2009;650:32-45.

17. Lieber MR, Gu J, Lu H, Shimazaki N, Tsai AG. Nonhomologous DNA end joining (NHEJ) and chromosomal translocations in humans. Subcell Biochem. 2010;50:279-96.

18. Tsai AG, Lieber MR. Mechanisms of chromosomal rearrangement in the human genome. BMC Genomics. 2010;11 Suppl 1:S1.

19. Chan TD, Brink R. Affinity-based selection and the germinal center response. Immunol Rev. 2012;247(1):11-23.

20. Fu YX, Chaplin DD. Development and maturation of secondary lymphoid tissues. Annu Rev Immunol. 1999;17:399-433.

21. Honjo T, Kinoshita K, Muramatsu M. Molecular mechanism of class switch recombination: linkage with somatic hypermutation. Annu Rev Immunol. 2002;20:165-96.

22. MacLennan IC, Toellner KM, Cunningham AF, Serre K, Sze DM, Zuniga E, et al. Extrafollicular antibody responses. Immunol Rev. 2003;194:8-18.

23. Muramatsu M, Kinoshita K, Fagarasan S, Yamada S, Shinkai Y, Honjo T. Class switch recombination and hypermutation require activationinduced cytidine deaminase (AID), a potential RNA editing enzyme. Cell. 2000;102(5):553-63.

24. Revy P, Muto T, Levy Y, Geissmann F, Plebani A, Sanal O, et al. Activationinduced cytidine deaminase (AID) deficiency causes the autosomal recessive form of the Hyper-IgM syndrome (HIGM2). Cell. 2000;102(5):565-75.

25. Chahwan R, Edelmann W, Scharff MD, Roa S. AIDing antibody diversity by error-prone mismatch repair. Seminars in Immunology. 2012;24(4):293-300.

26. Chaudhuri J, Basu U, Zarrin A, Yan C, Franco S, Perlot T, et al. Evolution of the immunoglobulin heavy chain class switch recombination mechanism. Adv Immunol. 2007:94:157-214.

27. Di Noia JM, Neuberger MS. Molecular mechanisms of antibody somatic hypermutation. Annu Rev Biochem. 2007;76:1-22.

28. Stavnezer J. Complex regulation and function of activation-induced cytidine deaminase. Trends Immunol. 2011;32(5):194-201.

29. Chaudhuri J, Alt FW. Class-switch recombination: interplay of transcription, DNA deamination and DNA repair. Nat Rev Immunol. 2004;4(7):541-52.

30. Chen Z, Wang JH. Generation and repair of AID-initiated DNA lesions in B lymphocytes. Front Med. 2014;8(2):201-16.

31. Okazaki IM, Hiai H, Kakazu N, Yamada S, Muramatsu M, Kinoshita K, et al. Constitutive expression of AID leads to tumorigenesis. J Exp Med. 2003;197(9):1173-81. 
32. Robbiani DF, Bunting S, Feldhahn N, Bothmer A, Camps J, Deroubaix S, et al. AID produces DNA double-strand breaks in non-lg genes and mature $B$ cell lymphomas with reciprocal chromosome translocations. Mol Cell. 2009; 36(4):631-41.

33. Robbiani DF, Bothmer A, Callen E, Reina-San-Martin B, Dorsett $Y$, Difilippantonio $S$, et al. AID is required for the chromosomal breaks in C-myc that lead to c-myc/lgH translocations. Cell. 2008;135(6):1028-38.

34. Lieber MR. The mechanism of double-strand DNA break repair by the nonhomologous DNA end-joining pathway. Annu Rev Biochem. 2010;79:181-211.

35. Boboila C, Alt FW, Schwer B. Classical and alternative end-joining pathways for repair of lymphocyte-specific and general DNA double-strand breaks. Adv Immunol. 2012:116:1-49.

36. Ochi T, Wu Q, Blundell TL. The spatial organization of non-homologous end joining: from bridging to end joining. DNA Repair (Amst). 2014;17:98-109.

37. Yan CT, Boboila C, Souza EK, Franco S, Hickernell TR, Murphy M, et al. IgH class switching and translocations use a robust non-classical end-joining pathway. Nature. 2007:449(7161):478-82.

38. Bassing $\mathrm{CH}$, Alt FW. The cellular response to general and programmed DNA double strand breaks. DNA Repair (Amst). 2004;3(8-9):781-96.

39. Difilippantonio MJ, Petersen S, Chen HT, Johnson R, Jasin M, Kanaar R, et al. Evidence for replicative repair of DNA double-strand breaks leading to oncogenic translocation and gene amplification. J Exp Med. 2002;196:469-80.

40. Difilippantonio MJ, Zhu J, Chen HT, Meffre E, Nussenzweig MC, Max EE, et al. DNA repair protein Ku80 suppresses chromosomal aberrations and malignant transformation. Nature. 2000;404(6777):510-4.

41. Frank KM, Sharpless NE, Gao Y, Sekiguchi JM, Ferguson DO, Zhu C, et al. DNA ligase IV deficiency in mice leads to defective neurogenesis and embryonic lethality via the p53 pathway. Mol Cell. 2000;5(6):993-1002.

42. Gao Y, Ferguson DO, Xie W, Manis JP, Sekiguchi J, Frank KM, et al. Interplay of p53 and DNA-repair protein XRCC4 in tumorigenesis, genomic stability and development. Nature. 2000;404(6780):897-900.

43. Zhu C, Mills KD, Ferguson DO, Lee C, Manis J, Fleming J, et al. Unrepaired DNA breaks in p53-deficient cells lead to oncogenic gene amplification subsequent to translocations. Cell. 2002;109(7):811-21.

44. Lane DP. Cancer. p53, guardian of the genome. Nature. 1992;358(6381):15-6.

45. Carr AM, Green MH, Lehmann AR. Checkpoint policing by p53. Nature. 1992:359(6395):486-7.

46. Bieging KT, Mello SS, Attardi LD. Unravelling mechanisms of p53-mediated tumour suppression. Nat Rev Cancer. 2014;14(5):359-70.

47. Wang JH, Alt FW, Gostissa M, Datta A, Murphy M, Alimzhanov MB, et al. Oncogenic transformation in the absence of Xrcc4 targets peripheral B cells that have undergone editing and switching. J Exp Med. 2008;205(13):3079-90.

48. Allman D, Lindsley RC, DeMuth W, Rudd K, Shinton SA, Hardy RR. Resolution of three nonproliferative immature splenic $B$ cell subsets reveals multiple selection points during peripheral B cell maturation. J Immunol. 2001;167(12):6834-40.

49. Casola S, Cattoretti G, Uyttersprot N, Koralov SB, Seagal J, Hao Z, et al. Tracking germinal center $B$ cells expressing germ-line immunoglobulin gamma1 transcripts by conditional gene targeting. Proc Natl Acad Sci U S A. 2006;103(19):7396-401.

50. Cory S, Graham M, Webb E, Corcoran L, Adams JM. Variant $(6 ; 15)$ translocations in murine plasmacytomas involve a chromosome 15 locus at least $72 \mathrm{~kb}$ from the c-myc oncogene. EMBO J. 1985;4(3):675-81.

51. Huppi K, Volfovsky N, Runfola T, Jones TL, Mackiewicz M, Martin SE, et al. The identification of microRNAs in a genomically unstable region of human chromosome 8q24. Molecular Cancer Research. 2008;6(2):212-21.

52. Decottignies A. Alternative end-joining mechanisms: a historical perspective. Frontiers in Genetics. 2013;4:48

53. Rogakou EP, Pilch DR, Orr AH, Ivanova VS, Bonner WM. DNA doublestranded breaks induce histone $\mathrm{H} 2 \mathrm{AX}$ phosphorylation on serine 139. J Biol Chem. 1998;273(10):5858-68.

54. Lee AJ, Endesfelder D, Rowan AJ, Walther A, Birkbak NJ, Futreal PA, et al. Chromosomal instability confers intrinsic multidrug resistance. Cancer Res. 2011;71(5):1858-70.

55. Roschke AV, Kirsch IR. Targeting karyotypic complexity and chromosomal instability of cancer cells. Curr Drug Targets. 2010;11(10):1341-50.

56. Negrini S, Gorgoulis VG, Halazonetis TD. Genomic instability-an evolving hallmark of cancer. Nat Rev Mol Cell Biol. 2010;11(3):220-8.

57. Moshous D, Pannetier C, Chasseval Rd R, Deist Fl F, Cavazzana-Calvo M, Romana S, et al. Partial T and B lymphocyte immunodeficiency and predisposition to lymphoma in patients with hypomorphic mutations in Artemis. J Clin Invest. 2003;111(3):381-7.

58. de Miranda NF, Peng R, Georgiou K, Wu C, Falk Sorqvist E, Berglund M, et al. DNA repair genes are selectively mutated in diffuse large $B$ cell lymphomas. J Exp Med. 2013;210(9):1729-42.

59. Du L, Peng R, Bjorkman A, Filipe de Miranda N, Rosner C, Kotnis A, et al. Cernunnos influences human immunoglobulin class switch recombination and may be associated with B cell lymphomagenesis. J Exp Med. 2012:209(2):291-305.

60. Toita N, Hatano N, Ono S, Yamada M, Kobayashi R, Kobayashi I, et al. Epstein-Barr virus-associated B-cell lymphoma in a patient with DNA ligase IV (LIG4) syndrome. American Journal of Medical Genetics Part A. 2007:143A(7):742-5.

61. Gaidano G, Ballerini P, Gong JZ, Inghirami G, Neri A, Newcomb EW, et al. p53 mutations in human lymphoid malignancies: association with Burkitt lymphoma and chronic lymphocytic leukemia. Proc Natl Acad Sci U S A. 1991:88(12):5413-7.

62. Rossi D, Spina V, Deambrogi C, Rasi S, Laurenti L, Stamatopoulos K, et al. The genetics of Richter syndrome reveals disease heterogeneity and predicts survival after transformation. Blood. 2011;117(12):3391-401.

63. Dalla-Favera R, Bregni M, Erikson J, Patterson D, Gallo RC, Croce CM. Human $c$-myc onc gene is located on the region of chromosome 8 that is translocated in Burkitt lymphoma cells. Proc Natl Acad Sci U S A. 1982;79(24):7824-7

64. Taub R, Kirsch I, Morton C, Lenoir G, Swan D, Tronick S, et al. Translocation of the c-myc gene into the immunoglobulin heavy chain locus in human Burkitt lymphoma and murine plasmacytoma cells. Proc Natl Acad Sci U S A. 1982:79(24):7837-41.

65. Janz S. Myc translocations in B cell and plasma cell neoplasms. DNA Repair (Amst). 2006:5(9-10):1213-24.

66. Kanungo A, Medeiros LJ, Abruzzo LV, Lin P. Lymphoid neoplasms associated with concurrent $\mathrm{t}(14 ; 18)$ and $8 \mathrm{q} 24 / \mathrm{c}-\mathrm{MYC}$ translocation generally have a poor prognosis. Mod Pathol. 2006;19(1):25-33.

67. Savage KJ, Johnson NA, Ben-Neriah S, Connors JM, Sehn LH, Farinha P, et al. MYC gene rearrangements are associated with a poor prognosis in diffuse large B-cell lymphoma patients treated with R-CHOP chemotherapy. Blood. 2009;114(17):3533-7.

68. Ramiro AR, Jankovic M, Eisenreich T, Difilippantonio S, Chen-Kiang S, Muramatsu $\mathrm{M}$, et al. AID is required for c-myc/lgH chromosome translocations in vivo. Cell. 2004;118(4):431-8.

69. Wang JH. Mechanisms and impacts of chromosomal translocations in cancers. Front Med. 2012;6(3):263-74.

70. Shiloh Y. ATM and related protein kinases: safeguarding genome integrity. Nat Rev Cancer. 2003;3(3):155-68.

71. Vogelstein B, Lane D, Levine AJ. Surfing the p53 network. Nature. 2000;408(6810):307-10.

72. Donehower LA, Harvey M, Slagle BL, McArthur MJ, Montgomery Jr CA, Butel JS, et al. Mice deficient for p53 are developmentally normal but susceptible to spontaneous tumours. Nature. 1992;356(6366):215-21.

73. Harvey M, McArthur MJ, Montgomery Jr CA, Bradley A, Donehower LA. Genetic background alters the spectrum of tumors that develop in p53-deficient mice. Faseb J. 1993;7(10):938-43.

74. Jacks T, Remington L, Williams BO, Schmitt EM, Halachmi S, Bronson RT, et al. Tumor spectrum analysis in p53-mutant mice. Curr Biol. 1994;4(1):1-7.

75. Liao MJ, Zhang XX, Hill R, Gao J, Qumsiyeh MB, Nichols W, et al. No requirement for $V(D) J$ recombination in p53-deficient thymic lymphoma. Mol Cell Biol. 2000;18(6):3495-501.

76. Gostissa M, Bianco JM, Malkin DJ, Kutok JL, Rodig SJ, Morse 3rd HC, et al. Conditional inactivation of p53 in mature B cells promotes generation of nongerminal center-derived B-cell lymphomas. Proc Natl Acad Sci U S A. 2013;110(8):2934-9.

77. Smith AD, Roda D, Yap TA. Strategies for modern biomarker and drug development in oncology. Journal of Hematology \& Oncology. 2014;7:70.

78. Cang S, Iragavarapu C, Savooji J, Song Y, Liu D. ABT-199 (venetoclax) and BCL-2 inhibitors in clinical development. Journal of Hematology \& Oncology. 2015:8(1):129.

79. Novero A, Ravella PM, Chen Y, Dous G, Liu D. Ibrutinib for B cell malignancies. Experimental Hematology \& Oncology. 2014;3(1):4.

80. Rai KR. Therapeutic potential of new B cell-targeted agents in the treatment of elderly and unfit patients with chronic lymphocytic leukemia. Journal of Hematology \& Oncology. 2015;8:85. 
81. Jonkers J, Meuwissen R, van der Gulden H, Peterse $H$, van der Valk M, Berns A. Synergistic tumor suppressor activity of BRCA2 and p53 in a conditional mouse model for breast cancer. Nat Genet. 2001;29(4):418-25.

82. Chen Z, Ranganath S, Viboolsittiseri SS, Eder MD, Chen X, Elos MT, et al. AID-initiated DNA lesions are differentially processed in distinct B cell populations. J Immunol. 2014;193(11):5545-56.

83. Wang J, Mullighan CG, Easton J, Roberts S, Heatley SL, Ma J, et al. CREST maps somatic structural variation in cancer genomes with base-pair resolution. Nat Methods. 2011;8(8):652-4.

84. Krzywinski M, Schein J, Birol I, Connors J, Gascoyne R, Horsman D, et al. Circos: an information aesthetic for comparative genomics. Genome Res. 2009;19(9):1639-45.

Submit your next manuscript to BioMed Central and we will help you at every step:

- We accept pre-submission inquiries

- Our selector tool helps you to find the most relevant journal

- We provide round the clock customer support

- Convenient online submission

- Thorough peer review

- Inclusion in PubMed and all major indexing services

- Maximum visibility for your research

Submit your manuscript at www.biomedcentral.com/submit
Biomed Central 